Correspondence

G. Balakrish Nair gbnair_2000@yahoo.com

Received 28 July 2008

Accepted 31 October 2008

\section{Peruvian Vibrio cholerae O1 El Tor strains possess a distinct region in the Vibrio seventh pandemic island-II that differentiates them from the prototype seventh pandemic El Tor strains}

Suraia Nusrin, ${ }^{1}$ Ana I. Gil, ${ }^{2}$ N. A. Bhuiyan, ${ }^{1}$ Ashrafus Safa, ${ }^{3}$ Masahiro Asakura, ${ }^{4}$ Claudio F. Lanata, ${ }^{2}$ E. Hall, ${ }^{5} \mathrm{H}$. Miranda, ${ }^{6}$ B. Huapaya, ${ }^{7}$ Carmen Vargas G., ${ }^{8}$ M. A. Luna, ${ }^{9}$ D. A. Sack, ${ }^{10}$ Shinji Yamasaki ${ }^{4}$ and $G$. Balakrish Nair ${ }^{11}$

\footnotetext{
${ }^{1}$ Enteric and Food Microbiology Unit, Laboratory Sciences Division, International Centre for Diarrhoeal Disease Research Bangladesh (ICDDR, B), Dhaka, Bangladesh

${ }^{2}$ Instituto de Investigación Nutricional, Lima, Peru

${ }^{3}$ Department of Biology and Chemistry, City University of Hong Kong, Kowloon, Hong Kong

${ }^{4}$ Graduate School of Life and Environmental Sciences, Osaka Prefecture University, Sakai, Osaka, Japan

${ }^{5}$ Naval Medical Research Center Detachment, Lima, Peru

${ }^{6}$ Instituto de Medicina Tropical e Infectologia, Facultad de Medicina, Universidad Nacional de Trujillo, Trujillo, Peru

${ }^{7}$ Instituto Nacional de Salud, Lima Peru

${ }^{8} \mathrm{CEPIS} / \mathrm{SDE} / \mathrm{OPS} / \mathrm{OMS}$, Lima, Peru

${ }^{9}$ Oficina General de Epidemiología, Lima, Peru

${ }^{10}$ Johns Hopkins Bloomberg School of Public Health, Baltimore, MD 21205, USA

${ }^{11}$ National Institute of Cholera and Enteric Diseases, P-33, CIT Scheme XM, Beliaghata, Kolkata 700010, India
}

\begin{abstract}
A collection of environmental and clinical strains of Vibrio cholerae $\mathrm{O} 1$ isolated from the beginning of the Latin American epidemic of cholera in 1991 to 2003 from multiple locations in Peru were characterized and compared with $V$. cholerae $\mathrm{O} 1 \mathrm{El}$ Tor strains of the seventh pandemic from the rest of the world (Asia, Africa, Australia and Europe) using a multilocus virulence gene profiling strategy and DNA sequencing. Peruvian strains differed from El Tor strains from the rest of the world by the failure of PCR to amplify genes VC0512, VC0513, VC0514 and VC0515 in the Vibrio seventh pandemic island-II (VSP-II) gene cluster. Sequencing of the VSP-II gene cluster and its flanking regions in one Peruvian strain (PERU-130) confirmed the PCR results, indicating that the Peruvian strain had low DNA homology (46.6\%) compared to the reference strain N16961 within the VSP-Il region encompassing genes VC0511 to VC0515. Based on these differences in VSP-II, and based on the overall similarity between the pulsotypes of the Peruvian strains and the El Tor reference strain N16961, we concluded that the Peruvian, Eurasian and African strains belonged to the same clonal complex, and that the Peruvian strains represented variants that had independently evolved for a relatively short time. Since these ORFs in VSP-II of Peruvian strains are unique and conserved, they could form the basis for tracking the origin of the Peruvian strains and therefore of the Latin American pandemic.
\end{abstract}




\section{INTRODUCTION}

In 1991, after an absence of more than a century, Vibrio cholerae $\mathrm{O} 1$ biotype El Tor entered into South America and caused explosive epidemics along the coast of Peru. Cholera occurred simultaneously at different sites along the Peruvian coast, over a distance of more than $1200 \mathrm{~km}$ (Seas et al., 2000). By the end of 1992, 19 countries in Latin America had reported more than 730000 cholera cases and 6300 deaths (Kaper et al., 1995; Popovic et al., 1993). The epidemic, thereafter, spread to the rest of South and Central America from Mexico to Argentina (Tauxe et al., 1995).

Since the entry of the El Tor biotype into Latin America, intensive efforts have been made to understand the origin of these strains. Molecular typing methods indicate that isolates from the 1991 Latin American epidemic were clonal and represented an extension of the seventh pandemic strain of El Tor biotype in the Western hemisphere (Wachsmuth et al., 1993). More recent studies have documented a relatively high rate of genetic changes as shown by changing serotypes, electrophoretic types (ETs), ribotypes and pulsotypes among the Latin American strains (Dalsgaard et al., 1997; Popovic et al., 1993; Evins et al., 1995). The current understanding is that there is a mélange of different molecular types among the Latin American strains of $V$. cholerae $\mathrm{O} 1$ closely related to the Asian and African seventh pandemic strains.

The past few years have witnessed many advances in our understanding of the genome and genetics of $V$. cholerae. We now know that the cholera toxin is encoded by a filamentous bacteriophage CTXФ (Waldor \& Mekalanos, 1996), and the toxin-coregulated pilus (TCP), an important colonization factor, acts as the receptor for CТXФ (Kovach et al., 1996; Karaolis et al., 1998). The rstR gene of RS1 satellite phage encodes a regulator of CTX $\Phi$ replication. The СТХ $\Phi$ types in $V$. cholerae strains are primarily recognized through the strain-specific rstR DNA sequence. The different types of CTX $\Phi$ and their corresponding $r s t R$ types have been described previously (Nusrin et al., 2004). $V$. cholerae, like other members of the genus Vibrio, has two circular chromosomes (Trucksis et al., 1998), and the whole genome sequence of an El Tor $V$. cholerae $\mathrm{O} 1$ strain N16961 has shown them to be 2.96 and $1.07 \mathrm{Mb}$ in size (Heidelberg et al., 2000). Comparative genomic analysis using DNA microarray showed that although they share a common lineage (O'Shea et al., 2004a) there are differences in gene content between the sixth (classical biotype) (representing the classical strains that caused the first six pandemics) and the current seventh (El Tor biotype) pandemic strains of $V$. cholerae $\mathrm{O} 1$, and identified two genomic regions designated the Vibrio seventh pandemic island-I (VSP-I) and VSP-II that are unique to seventh pandemic El Tor strains (Dziejman et al., 2002). VSP-I and VSP-II showed several properties of pathogenicity islands, and are believed to be involved with the pandemic tendency of the seventh pandemic El Tor strains.
In light of the new information on the molecular aspects of $V$. cholerae, we decided to re-examine the strains of $V$. cholerae O1 isolated from the beginning of the Peruvian epidemic in 1991 to 2003 from different locations in Peru, using a PCR-based multilocus virulence gene profiling strategy. We report the identification of a distinct and conserved molecular signature in the Peruvian strains in the VSP-II cluster not seen in other seventh pandemic strains of $V$. cholerae $\mathrm{O} 1 \mathrm{El}$ Tor.

\section{METHODS}

Bacterial strains. A total of $60 \mathrm{~V}$. cholerae $\mathrm{O} 1$ strains (48 clinical and 12 environmental) isolated from Lima, Trujillo, Lambayeque, Cajamarca, Arequipa, Ayacucho, Loreto and Ucayali in Peru from 1991 to 2003 were examined. Twenty-three $V$. cholerae O1 El Tor strains from ten other countries (Table 1) were also included in this study for comparison. V. cholerae O1 classical O395 and El Tor strain N16961 strains were used as reference strains representing both the biotypes of $V$. cholerae $\mathrm{O} 1$. All strains were subcultured on gelatin agar plates and were stored at $-80{ }^{\circ} \mathrm{C}$ in Luria-Bertani (LB) broth (Miller) containing $25 \%$ glycerol until needed for further study.

Serotyping and biotyping. The serogroup of all strains was reconfirmed using polyvalent $\mathrm{O} 1$ and monoclonal Inaba and Ogawa antisera prepared at the International Centre for Diarrhoeal Disease Research, Bangladesh (ICDDR, B). Biotyping included tests for polymyxin B susceptibility (50 U), chicken red blood cell agglutination and sensitivity to group IV classical and group $5 \mathrm{El}$ Tor phages, and tests were performed as described previously (Nair et al., 2002).

Genomic DNA isolation. In brief, cells were harvested from $3 \mathrm{ml}$ overnight culture in LB broth and they were then subjected to alkaline lysis, and proteinase and RNase treatment. This was followed by phenol/chloroform extraction and precipitation of the nucleic acid in the presence of 2-propanol (Chowdhury et al., 2000). Excess salt was removed by a $70 \%$ alcohol wash and the nucleic acid was air-dried and resuspended in sterile TE buffer. The concentration and purity of the DNA was assayed using a spectrophotometer (GeneQuant) and the DNA was stored at $-20{ }^{\circ} \mathrm{C}$ for subsequent experiments.

\section{PCR analysis}

Confirmation of strain identity. All strains were confirmed as $V$. cholerae using species-specific ompW PCR (Nandi et al., 2000). Multiplex PCR was used to detect O-antigen biosynthesis genes ( $w b e$ or $w b f$ ) and for the cholera toxin A-encoding gene (ctxA) (Hoshino et al., 1998). Alleles of the tcpA (Keasler \& Hall, 1993) and rtsR genes (Davis et al., 1999) were identified by PCR using primers and procedures described previously (Nusrin et al., 2004). All PCR reagents and kits were obtained from Invitrogen.

Multilocus virulence gene profiling. Multilocus virulence gene profiling by PCR was used to scan 11 virulence-associated genes and/or gene clusters and a housekeeping gene in the genome of 20 Peruvian V. cholerae isolates, including reference O395 classical and N16961 El Tor strains, using 31 sets of PCR primers and conditions described elsewhere (O'Shea et al., 2004a; Chow et al., 2001; Rivera et al., 2001; Nair et al., 2006; Safa et al., 2006). The PCR products were subjected to agarose gel electrophoresis, stained with ethidium bromide, visualized under UV light and the results recorded by a gel documentation system (Gel Doc 2000; Bio-Rad). The sizes of the PCR products were determined by comparison with different molecular size markers. 
Table 1. Serotypes and genotypes of the $V$. cholerae O1 El Tor biotype strains and the two reference strains examined in this study

\begin{tabular}{|c|c|c|c|c|c|}
\hline \multirow{2}{*}{$\begin{array}{l}\text { Country } \\
\text { (no. of strains) or } \\
\text { reference strain }\end{array}$} & \multirow{2}{*}{$\begin{array}{c}\text { Year of } \\
\text { isolation }\end{array}$} & \multirow[t]{2}{*}{ Serotype } & \multicolumn{3}{|c|}{ Genotype } \\
\hline & & & $\operatorname{ctxA}$ & $t c p A$ & $r s t R^{\star}$ \\
\hline Peru (47) & 1991-1999, 2003 & Ogawa & + & + & 2 \\
\hline Peru (10) & 1991-1994 & Inaba & + & + & 2 \\
\hline Peru (1) & 1991 & Inaba & + & - & 2 \\
\hline Peru (1) & 1995 & Ogawa & - & + & 2 \\
\hline Peru (1) & 1993 & Ogawa & + & - & 2 \\
\hline Australia (1) & 1986 & Inaba & + & + & 1 \\
\hline Australia (1) & 1965 & Inaba & - & - & - \\
\hline Australia (1) & 1979 & Inaba & + & + & 1,2 \\
\hline Bangladesh (4) & 2004 & Ogawa & + & + & 2 \\
\hline India (2) & 1975,1982 & Ogawa & + & + & 2 \\
\hline India (1) & 1981 & Ogawa & - & + & 2 \\
\hline Maldives (1) & 1978 & Ogawa & + & + & 2 \\
\hline Maldives (1) & 1978 & Ogawa & - & + & 2 \\
\hline Malaysia (1) & 1978 & Inaba & + & + & 2 \\
\hline Malaysia (1) & 1978 & Ogawa & + & + & 2 \\
\hline Myanmar (1) & 1970 & Ogawa & + & + & 1,2 \\
\hline Macao, China (1) & 1970 & Inaba & - & + & 2 \\
\hline Germany (1) & 1975 & Inaba & + & + & 2 \\
\hline Germany (1) & 1975 & Ogawa & + & + & 2 \\
\hline Zambia (2) & 1996, 2003 & Ogawa & + & + & 2 \\
\hline Mozambique (3) & 2004 & Ogawa & + & + & 1 \\
\hline O395 (classical) & 1965 & Ogawa & + & + & 1 \\
\hline N16961 (El Tor) & 1971 & Inaba & + & + & 2 \\
\hline
\end{tabular}

${ }^{*} r s t R 1$ and $r s t R 2$ represent the $r s t R$ genes of classical and El Tor type, respectively.

ORF content analysis of VSP-II region. The presence or absence of ORFs in the VSP-II cluster of $83 \mathrm{~V}$. cholerae O1 isolates (60 Peruvian strains and 23 strains from different parts of the world) was reexamined by PCR using primers described elsewhere (O'Shea et al., 2004a) with new combinations and PCR conditions, as shown in Table 2. Five sets of primers were designed (Table 2) from the VSP-II DNA sequence of reference N16961 El Tor strain (accession number NC_002505) using GeneFisher software (available at http:// www.genefisher.de/) to examine the individual ORFs of VSP-II region that encompasses VC0511 to VC0515. PCR conditions are given in Table 2.

\section{Nucleotide sequence analysis}

VSP-II gene cluster. The entire VSP-II region of Peruvian strain PERU-130 was amplified by PCR using Ex Taq (Takara Bio) and primers shown in Table 2 . The PCR product obtained by using LA Taq (Takara Bio) and the primer set VSPII LaU and VSPII LaR was digested by Sau3AI. The digests were ligated into the BamHI site of pBluescript II SK (-) and the ligation mixture was used to transform E. coli JM109. The recombinant E. coli strains were cultured in L broth including ampicillin $\left(100 \mu \mathrm{g} \mathrm{ml}^{-1}\right)$ and an aliquot was boiled in TE buffer. The boiled template was amplified by M13 forward and reverse primers. All the PCR products were purified by QIAquick PCR purification kit (Qiagen) and sequenced using an ABI Prism BigDye terminator cycle sequencing ready reaction kit (Applied Biosystems), and M13 forward and reverse primers, or sequencing primer designed by the obtained sequence, if necessary. The reactions were conducted in a GeneAmp 9700 thermal cycler in accordance with the manufacturer's instruction (Applied Biosystems). The nucleotide sequence was determined using an ABI Prism 3100Avant genetic analyser (Applied Biosystems). VSP-II DNA sequences obtained were analysed using the DNA Lasergene software package (DNASTAR). Homology searches were performed using the BLAST program made available by DNA Data Bank Japan (DDBJ). The DNA sequence of VSP-II was submitted to DDBJ under the accession number AB300724.

ctx $B$ gene. To determine the $c t x B$ nucleotide sequence, PCR amplification of $\operatorname{ctxB}$ gene of three Peruvian $V$. cholerae O1 representative strains (PERU-044, PERU-130 and PERU-296) was performed in an automated Peltier thermal cycler (PTC-200; M. J. Research) using PCR primers and conditions described previously (Mitra et al., 2001). PCR products were purified with a Microcon centrifugal filter device (Millipore) and sequenced using an ABI PRISM BigDye terminator cycle sequencing reaction kit (PerkinElmer Applied Biosystems) with an ABI PRISM 310 automated sequencer. The chromatogram sequencing files were inspected using Chromas 2.23 (Technelysium). The $\operatorname{ctxB}$ nucleotide sequences obtained were compared with that of the reference N16961 El Tor strain (GenBank accession no. NC_002505) and 569B classical strain (GenBank accession no. U25679) retrieved from GenBank using BLAST. Multiple sequence alignments were developed using CLUSTAL_X 1.81.13. The nucleotide sequences of the $\operatorname{ctx} B$ genes have been deposited in GenBank under accession numbers EU921452EU921454. 
Table 2. PCR primer sequences and conditions for analysing the VSP-II region of $V$. cholerae O1 El Tor strains isolated in Peru and various other countries

\begin{tabular}{|c|c|c|c|c|c|c|c|}
\hline \multirow[t]{2}{*}{ Primer designation } & \multirow[t]{2}{*}{ Sequences $\left(5^{\prime} \rightarrow 3^{\prime}\right)$} & \multicolumn{3}{|c|}{ PCR condition } & \multirow{2}{*}{$\begin{array}{l}\text { No. of } \\
\text { cycles }\end{array}$} & \multirow{2}{*}{$\begin{array}{l}\text { Product size } \\
\quad(b p)\end{array}$} & \multirow[t]{2}{*}{ Reference } \\
\hline & & Denaturation & Annealing & Extension & & & \\
\hline VC0511F1 & CTTGCTGCGTACTTAGCA & $95^{\circ} \mathrm{C}, 1 \mathrm{~min}$ & $54{ }^{\circ} \mathrm{C}, 1 \mathrm{~min}$ & $72{ }^{\circ} \mathrm{C}, 1 \mathrm{~min}$ & 30 & 385 & This study \\
\hline VC0511R1 & AGTAGCATCGCTCTCGTA & & & & & & \\
\hline VC0512F1 & TCCTGATTGGGAGCGAA & $95^{\circ} \mathrm{C}, 1 \mathrm{~min}$ & $54{ }^{\circ} \mathrm{C}, 1 \mathrm{~min}$ & $72{ }^{\circ} \mathrm{C}, 1 \mathrm{~min}$ & 30 & 1704 & This study \\
\hline VC0512R1 & TCACGCGGGTTATTCCA & & & & & & \\
\hline VC0513F1 & CTGAGGTGTTATATGTTTCG & $95^{\circ} \mathrm{C}, 1 \mathrm{~min}$ & $54{ }^{\circ} \mathrm{C}, 1 \mathrm{~min}$ & $72{ }^{\circ} \mathrm{C}, 1 \mathrm{~min}$ & 30 & 781 & This study \\
\hline VC0513R1 & TCAAATTTCCTGACAGTTCC & & & & & & \\
\hline VC0514F1 & GTTTGGGAAGGGTACACA & $95^{\circ} \mathrm{C}, 1 \mathrm{~min}$ & $52{ }^{\circ} \mathrm{C}, 1 \mathrm{~min}$ & $72{ }^{\circ} \mathrm{C}, 1 \mathrm{~min}$ & 30 & 1651 & This study \\
\hline VC0514R1 & GCTCTTCAGCCGCTGA & & & & & & \\
\hline VC0515F1 & GGTGGTGCTGCATGGA & $95^{\circ} \mathrm{C}, 1 \mathrm{~min}$ & $50{ }^{\circ} \mathrm{C}, 1 \mathrm{~min}$ & $72{ }^{\circ} \mathrm{C}, 1 \mathrm{~min}$ & 30 & 1135 & This study \\
\hline VC0515R1 & TCTAAAGCCTCACACCA & & & & & & \\
\hline VC0489F & AGATCAACTACGATCAAGCC & $94^{\circ} \mathrm{C}, 30 \mathrm{~s}$ & $52{ }^{\circ} \mathrm{C}, 30 \mathrm{~s}$ & $72{ }^{\circ} \mathrm{C}, 4 \mathrm{~min}$ & 30 & 5202 & O'Shea et al. (2004a) \\
\hline VC0490R & TGCAGTTGTTGAATGGAC & & & & & & \\
\hline VC0490F & CGTGAAGGGATATAGGAG & $94^{\circ} \mathrm{C}, 30 \mathrm{~s}$ & $52{ }^{\circ} \mathrm{C}, 30 \mathrm{~s}$ & $72{ }^{\circ} \mathrm{C}, 4 \mathrm{~min}$ & 30 & 6718 & O'Shea et al. (2004a) \\
\hline VC0493R & CGCTCTTCTTTCCACGCTTCA & & & & & & \\
\hline VC0493F & AATGCTTCTCAGGGGGGTCTT & $94{ }^{\circ} \mathrm{C}, 30 \mathrm{~s}$ & $52{ }^{\circ} \mathrm{C}, 30 \mathrm{~s}$ & $72{ }^{\circ} \mathrm{C}, 4 \mathrm{~min}$ & 30 & 7439 & O'Shea et al. (2004a) \\
\hline VC0498R & TGCGGCTCCAATGGAGTCTG & & & & & & \\
\hline VC0502F & TCATCAGTTAGCACACGAAC & $94^{\circ} \mathrm{C}, 30 \mathrm{~s}$ & $52{ }^{\circ} \mathrm{C}, 30 \mathrm{~s}$ & $72{ }^{\circ} \mathrm{C}, 4 \mathrm{~min}$ & 30 & 5808 & O'Shea et al. (2004a) \\
\hline VC0504R & AGCCCGAAATGAATCCCAAAA & & & & & & \\
\hline VC0504F & CAGCAAAGGCGGAAGAGGTAG & $94^{\circ} \mathrm{C}, 30 \mathrm{~s}$ & $52{ }^{\circ} \mathrm{C}, 30 \mathrm{~s}$ & $72{ }^{\circ} \mathrm{C}, 4 \mathrm{~min}$ & 30 & 7616 & O'Shea et al. (2004a) \\
\hline VC0512R & CССTCCACTGCTATTCCG & & & & & & \\
\hline VC0512F & CAGTGGCTTCGCAGAGGA & $94^{\circ} \mathrm{C}, 30 \mathrm{~s}$ & $52{ }^{\circ} \mathrm{C}, 30 \mathrm{~s}$ & $72{ }^{\circ} \mathrm{C}, 4 \mathrm{~min}$ & 30 & 8384 & O'Shea et al. (2004a) \\
\hline VC0516R & TCCTGATGTCTCTCTTGCCG & & & & & & \\
\hline VC0514F & TTATGATCCAAGGAGTAGGG & $94^{\circ} \mathrm{C}, 30 \mathrm{~s}$ & $52{ }^{\circ} \mathrm{C}, 30 \mathrm{~s}$ & $72{ }^{\circ} \mathrm{C}, 4 \mathrm{~min}$ & 30 & 6736 & O'Shea et al. (2004a) \\
\hline VC0517R & CGCAGTCACAGCTTAAAC & & & & & & \\
\hline VSPII LaU & CGCACATACTCTTTGGTGGCATCAG & $98{ }^{\circ} \mathrm{C}, 10 \mathrm{~s}$ & & $68{ }^{\circ} \mathrm{C}, 10 \mathrm{~min}$ & 30 & 10091 & This study \\
\hline VSPII LaR & ACTCTCTCTGATGGTGATGGCCTTC & & & & & & \\
\hline VSPII $47 \mathrm{U}$ & TGTCACCTGAAGCTACAG & $94^{\circ} \mathrm{C}, 30 \mathrm{~s}$ & $52{ }^{\circ} \mathrm{C}, 30 \mathrm{~s}$ & $72{ }^{\circ} \mathrm{C}, 2 \mathrm{~min}$ & 30 & 2822 & This study \\
\hline VC0517R & CGCAGTCACAGCTTAAAC & & & & & & \\
\hline
\end{tabular}


PFGE. Intact agarose-embedded chromosomal DNA from the $V$. cholerae strains was prepared and PFGE was performed using a contour-clamped homogeneous electric field apparatus (CHEFMapper) (Bio-Rad) following the standardized PFGE protocol (Cooper et al., 2006). Genomic DNA was digested with NotI enzyme (Invitrogen). The restriction fragments were separated in $1 \%$ SeaKem Gold agarose in $0.5 \times$ TBE buffer $(45 \mathrm{mM}$ Tris $/ 44 \mathrm{mM}$ borate/ $0.8 \mathrm{mM}$ EDTA). V. cholerae N16961 and 569B were used as reference strains. Salmonella enterica serotype Braenderup strain H9812 digested with $\mathrm{XbaI}$ (Invitrogen) was used as the molecular size marker. Following electrophoresis, the gels were stained with ethidium bromide, destained with water and images were captured using a gel documentation system (Gel Doc 2000; Bio-Rad).

\section{RESULTS AND DISCUSSION}

\section{Confirmation of strain identity}

$V$. cholerae species-specific ompW and serogroup-specific wbe PCR were positive for all the 83 strains tested from Peru and 10 other countries (data not shown). Biotyping showed that all strains were resistant to polymyxin B, agglutinated with chicken erythrocytes, were resistant to phage IV and sensitive to phage 5 , which are typical traits of the El Tor biotype. Among the 60 Peruvian strains, 2 strains (PERU-067 and PERU-189) were negative for tcpA of both the El Tor and classical type, while others were positive for $t c p A$ of the El Tor type (Table 1). All Peruvian strains harboured an $r s t R$ gene of El Tor type. $r s t R$ types found in other strains are shown in Table 1. The serotype and genotype of the 60 Peruvian strains and the 23 strains of $V$. cholerae $\mathrm{O} 1$ from other countries are shown in Table 1. All strains from Peru except one were $c t x A$ positive, and only four strains from other countries were negative for this gene. Deduced amino acid sequences from $\operatorname{ctx} B$ genes of representative Peruvian strains were identical to that of the reference N16961 El Tor strain. Therefore, the $\operatorname{ctxB}$ of Peruvian strains were categorized as genotype 3, which includes $V$. cholerae strains of Latin American origin and the strains of the current seventh pandemic clone.

Serogrouping and biotyping of Peruvian V. cholerae strains revealed that all strains belonged to serogroup $\mathrm{O} 1$ and to the El Tor biotype. Examination of biotype-specific genotypic traits also confirmed that the Peruvian strains were of the El Tor biotype. Presence of critical virulenceassociated genes $t c p A$ and $\operatorname{ct} x A B$ in the Peruvian strains suggested that almost all strains were virulent and had the potential to cause epidemic outbreaks.

\section{Multilocus virulence gene profiling}

Of the 60 Peruvian strains, 20 (Table 3) representative strains and reference strains O395 (classical) and N16961 (El Tor) were examined for 11 virulence-associated genes and/or gene clusters and for a housekeeping gene $(m d h)$ by PCR. All 20 strains from Peru showed the presence of all genes comprising VSP-I, MSHA and RTX gene clusters; five individual loci, namely $h l y A$, pile, tlc, intl4 and $r s t C$, were also present in all the Peruvian strains examined (Table 3). Apart from this, two Peruvian strains lacked the genes of the VPI-I region examined and one strain was negative for $c t x A B$ genes, and therefore, it was concluded to be non-toxigenic (Table 3). Among the ORFs of VSP-II examined in the preliminary genetic screen, two ORFs, namely VC0512 and VC0514, were negative by PCR in all 20 Peruvian strains tested, including the O395 classical reference strains but they were present in the N16961 El Tor reference strain (Table 3).

Screening of 11 virulence-associated genes and/or gene clusters of Peruvian strains and their comparison with the typical seventh-pandemic El Tor strain indicated that Peruvian strains are similar to the seventh pandemic strains with regard to their pathogenic potential. The only significant disparity observed between the virulence gene content of the Peruvian and typical seventh pandemic strains was confined to the putative virulence gene cluster, VSP-II. The altered gene content of the VSP-II cluster of Peruvian strains distinguished them from the Eurasian and African prototype seventh pandemic El Tor strains.

\section{VSP-II gene cluster analysis}

Our next objective was to examine the absence of ORFs 512 and 514 in VSP-II and their flanking regions in further detail. PCR screening of 60 Peruvian strains for 12 ORFs of VSP-II revealed that all strains were positive for ORFs VC0498VC0502, VC0504-VC0510 and VC0517, whereas ORFs VC0512-VC0515 could not be amplified in any of the Peruvian strains (Table 4). ORF VC0511was absent in 51 strains and 40 strains were negative for VC0516 (Table 4). ORFs VC0490 and VC0493 were not found in strain PERU044 and PERU-001, respectively. Except for three strains from Australia, all ORFs of VSP-II examined were found in all strains from other countries (Table 4). Three Australian strains were negative for the complete VSP-II region.

Comparative genomic analysis of diverse $V$. cholerae has recently shown that VSP-I and VSP-II gene clusters are unique to the seventh pandemic El Tor biotype strains but absent in strains of the classical biotype. The role of VSP-I and VSP-II in the El Tor biotype is not known (O'Shea et al., 2004a) but their exclusive presence among the seventh pandemic El Tor strains is responsible for some of the distinctive properties of this biotype (Dziejman et al., 2002), and may contribute in some way to its fitness and survival (O'Shea et al., 2004a). VSP-II is a $29.6 \mathrm{~kb}$ genomic island encompassing 24 predicted ORFs (VC0490VC0516) encoding proteins including DNA repair and methyl-accepting chemotaxis proteins, a group of hypothetical proteins and a bacteriophage-like integrase adjacent to a tRNA-encoding gene (O'Shea et al., 2004b). By PCR analysis, we discovered that the Peruvian El Tor strains of $V$. cholerae O1 have an intact VSP-I but found altered gene content for the VSP-II cluster as PCR could not amplify some ORFs, namely VC0512 (methyl-accepting chemotaxis protein), VC0513 (transcriptional regulator), 
Table 3. Results of the genetic screen used for identifying 11 virulence regions and one housekeeping gene of the $V$. cholerae O1 strains isolated in Peru between 1991 and 2003

\begin{tabular}{|c|c|c|c|c|c|c|c|c|c|c|c|c|c|c|c|c|c|c|c|c|c|c|c|c|c|c|c|c|c|c|c|c|}
\hline \multirow[t]{2}{*}{ Strain } & \multirow{2}{*}{ Biotype } & \multirow{2}{*}{$\begin{array}{c}\begin{array}{c}\text { Housekeeping } \\
\text { gene }\end{array} \\
m d h\end{array}$} & \multicolumn{5}{|c|}{ VSP-I } & \multicolumn{4}{|c|}{ MSHA } & \multirow{2}{*}{$\begin{array}{r}\text { hlyA } \\
489\end{array}$} & \multicolumn{7}{|c|}{ VSP-II } & \multicolumn{3}{|c|}{ VPI-I } & \multirow{2}{*}{$\begin{array}{l}\text { pile } \\
\text { pile }\end{array}$} & \multicolumn{2}{|c|}{ RTX } & \multirow{2}{*}{$\frac{\text { RS1 }}{r s t C}$} & \multicolumn{4}{|c|}{ СТX } & \multirow{2}{*}{$\frac{\text { TLC }}{t l c}$} & \\
\hline & & & 1751 & 178 & 180 & 183 & 185 & 3984 & 4004 & 4034 & 406 & & 490 & $491-496$ & $498-502$ & 504-510 & $512-515$ & 516 & 517 & $t c p A$ & toxT & $a c f B$ & & $r t x A$ & $r t x C$ & & $r s t A$ & $\operatorname{orf} U$ & $z o t$ & $c t x A B$ & & \\
\hline PERU-130* & El Tor & + & + & + & + & + & + & + & + & + & + & + & + & + & + & + & - & + & + & $\mathrm{E}$ & + & + & + & + & + & + & + & + & + & + & + & + \\
\hline PERU-139* & El Tor & + & + & + & + & + & + & + & + & + & + & + & + & + & + & + & - & + & + & $\mathrm{E}$ & + & + & + & + & + & + & + & + & + & + & + & + \\
\hline PERU-067* ${ }^{*}$ & El Tor & + & + & + & + & + & + & + & + & + & + & + & + & + & + & + & - & + & + & - & - & - & + & + & + & + & + & + & + & + & + & + \\
\hline PERU-115* & El Tor & + & + & + & + & + & + & + & + & + & + & + & + & + & + & + & - & + & + & $\mathrm{E}$ & + & + & + & + & + & + & + & + & + & + & + & + \\
\hline PERU-044* & El Tor & + & + & + & + & + & + & + & + & + & + & + & - & + & + & + & - & + & + & E & + & + & + & + & + & + & + & + & + & + & + & + \\
\hline PERU-097* & El Tor & + & + & + & + & + & + & + & + & + & + & + & + & + & + & + & - & + & + & $\mathrm{E}$ & + & + & + & + & + & + & + & + & + & - & + & + \\
\hline PERU-120* & El Tor & + & + & + & + & + & + & + & + & + & + & + & + & + & + & + & - & + & + & E & + & + & + & + & + & + & + & + & + & + & + & + \\
\hline PERU-169* & El Tor & + & + & + & + & + & + & + & + & + & + & + & + & + & + & + & - & + & + & $\mathrm{E}$ & + & + & + & + & + & + & + & + & + & + & + & + \\
\hline PERU-037* & El Tor & + & + & + & + & + & + & + & + & + & + & + & + & + & + & + & - & + & + & $\mathrm{E}$ & + & + & + & + & + & + & + & + & + & + & + & + \\
\hline PERU-299† & El Tor & + & + & + & + & + & + & + & + & + & + & + & + & + & + & + & - & + & + & $\mathrm{E}$ & + & + & + & + & + & + & + & + & + & + & + & + \\
\hline PERU-189 $\ddagger$ & El Tor & + & + & + & + & + & + & + & + & + & + & + & + & + & + & + & - & + & + & - & - & - & + & + & + & + & + & + & + & + & + & + \\
\hline PERU-200 $\ddagger$ & El Tor & + & + & + & + & + & + & + & + & + & + & + & + & + & + & + & - & + & + & $\mathrm{E}$ & + & + & + & + & + & + & + & + & + & + & + & + \\
\hline PERU-205‡ & El Tor & + & + & + & + & + & + & + & + & + & + & + & + & + & + & + & - & + & + & $\mathrm{E}$ & + & + & + & + & + & + & + & + & + & + & + & + \\
\hline PERU-219 $\ddagger$ & El Tor & + & + & + & + & + & + & + & + & + & + & + & + & + & + & + & - & + & + & $\mathrm{E}$ & + & + & + & + & + & + & + & + & + & + & + & + \\
\hline PERU-306 ${ }^{\dagger}$ & El Tor & + & + & + & + & + & + & + & + & + & + & + & + & + & + & + & - & + & + & $\mathrm{E}$ & + & + & + & + & + & + & + & + & + & + & + & + \\
\hline PERU-324 $\ddagger$ & El Tor & + & + & + & + & + & + & + & + & + & + & + & + & + & + & + & - & + & + & $\mathrm{E}$ & + & + & + & + & + & + & + & + & + & + & + & + \\
\hline PERU-327 $\$$ & El Tor & + & + & + & + & + & + & + & + & + & + & + & + & + & + & + & - & + & + & E & + & + & + & + & + & + & + & + & + & + & + & + \\
\hline PERU-328 & El Tor & + & + & + & + & + & + & + & + & + & + & + & + & + & + & + & - & + & + & $\mathrm{E}$ & + & + & + & + & + & + & + & + & + & + & + & + \\
\hline PERU-329 $\ddagger$ & El Tor & + & + & + & + & + & + & + & + & + & + & + & + & + & + & + & - & + & + & E & + & + & + & + & + & + & + & + & + & + & + & + \\
\hline PERU-330 $\ddagger$ & El Tor & + & + & + & + & + & + & + & + & + & + & + & + & + & + & + & - & + & + & $\mathrm{E}$ & + & + & + & + & + & + & + & + & + & + & + & + \\
\hline N16961 & El Tor & + & + & + & + & + & + & + & + & + & + & + & + & + & + & + & + & + & + & $\mathrm{E}$ & + & + & + & + & + & + & + & + & + & + & + & + \\
\hline O395 & Classical & + & - & - & - & - & - & + & + & + & + & + & - & - & - & - & - & - & - & C & + & + & + & + & - & - & + & + & + & + & + & + \\
\hline
\end{tabular}

C, Classical tcpA; E, El Tor $t c p A$.

${ }^{*}$ Clinical origin.

†Unknown origin.

‡Environmental origin. 
Table 4. Comparison of the VSP-II regions of Peruvian V. cholerae O1 El Tor isolates with those of the isolates from different countries possessing different ORFs of the VSP-II region

\begin{tabular}{|c|c|c|c|c|c|c|c|c|c|c|c|c|c|}
\hline \multirow{2}{*}{$\begin{array}{l}\text { Place of } \\
\text { isolation }\end{array}$} & \multirow{2}{*}{$\begin{array}{l}\text { No. of } \\
\text { strains }\end{array}$} & \multicolumn{12}{|c|}{ VSP-II } \\
\hline & & $\begin{array}{l}\text { VC0490- } \\
\text { VC0492* }\end{array}$ & $\begin{array}{l}\text { VC0493- } \\
\text { VC0496 }\end{array}$ & $\begin{array}{l}\text { VC0498- } \\
\text { VC0502 }^{*}\end{array}$ & $\mathrm{VC}^{2} 502^{*}$ & $\begin{array}{l}\text { VC0504- } \\
\text { VC0510 }\end{array}$ & VC0511† & VC0512† & VC0513† & VC0514† & VC0515† & VC0516* & VC0517* \\
\hline Peru & 30 & + & + & + & + & + & - & - & - & - & - & - & + \\
\hline Peru & 19 & + & + & + & + & + & - & - & - & - & - & + & + \\
\hline Peru & 9 & + & + & + & + & + & + & - & - & - & - & - & + \\
\hline Peru & 1 & - & + & + & + & + & - & - & - & - & - & + & + \\
\hline Peru & 1 & + & - & + & + & + & - & - & - & - & - & - & + \\
\hline Australia & 3 & - & - & - & - & - & - & - & - & - & - & - & + \\
\hline Bangladesh & 4 & + & - & - & + & + & + & + & + & + & + & + & + \\
\hline Myanmar & 1 & + & + & + & + & + & + & + & + & + & + & + & + \\
\hline India & 3 & + & + & + & + & + & + & + & + & + & + & + & + \\
\hline Maldives & 2 & + & + & + & + & + & + & + & + & + & + & + & + \\
\hline Malaysia & 2 & + & + & + & + & + & + & + & + & + & + & + & + \\
\hline Mozambique & 3 & + & + & + & + & + & + & + & + & + & + & + & + \\
\hline Macao, China & 1 & + & + & + & + & + & + & + & + & + & + & + & + \\
\hline Germany & 2 & + & + & + & + & + & + & + & + & + & + & + & + \\
\hline Zambia & 1 & + & + & + & + & + & + & + & + & + & + & + & + \\
\hline Zambia & 1 & + & - & - & + & + & + & + & + & + & + & + & + \\
\hline $\begin{array}{c}\text { Classical } \\
\text { (O395) }\end{array}$ & 1 & - & - & - & - & - & - & - & - & - & - & - & + \\
\hline $\begin{array}{l}\text { El Tor } \\
\text { (N16961) }\end{array}$ & 1 & + & + & + & + & + & + & + & + & + & + & + & + \\
\hline
\end{tabular}

${ }^{\star}$ The ORFs VC0490-VC0504 and the ORFs VC0516-VC0517 were amplified with the primers described by O'Shea et al. (2004a).

†The ORFs VC0511-VC0515 were amplified with the primers designed in this study (Table 2). 


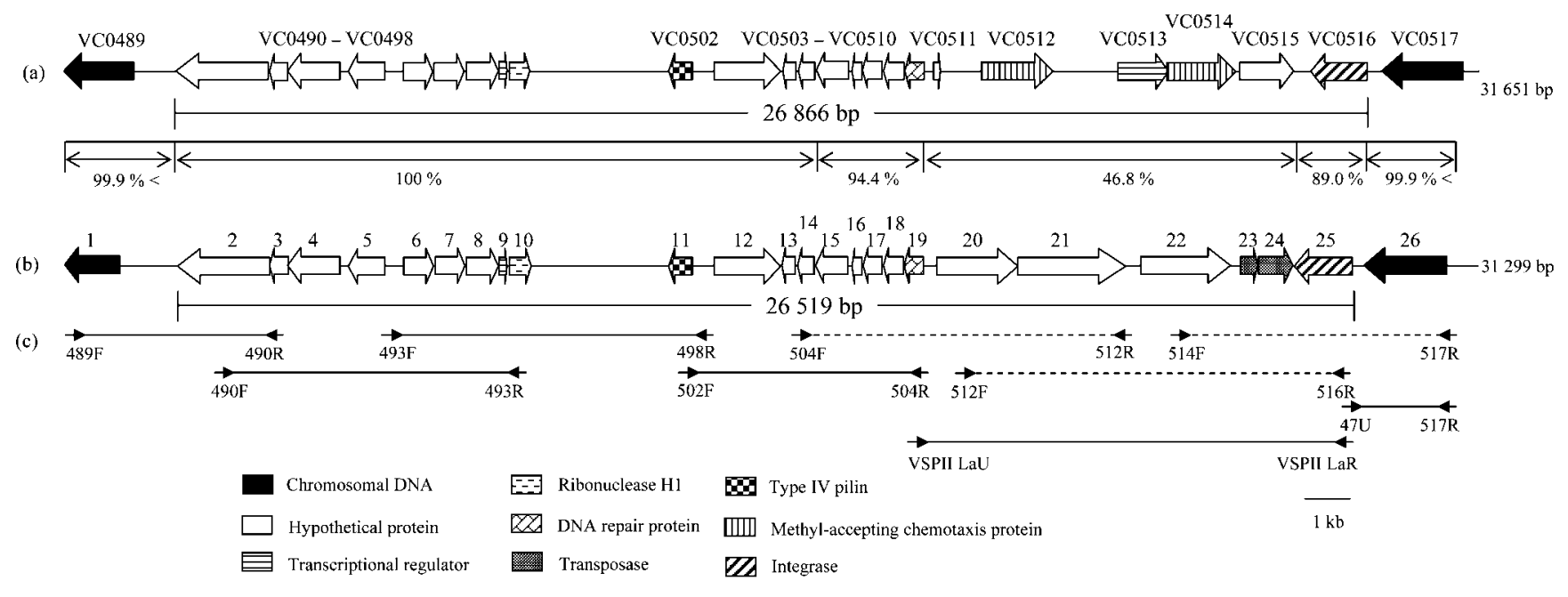

Fig. 1. Schematic representation of the organization of VSP-II from V. cholerae strains N16961 (a) and PERU-130 (b). The position and direction of transcription of the ORFs are indicated by the arrows. Homology between N16961 and PERU-130 at the DNA level is described as a percentage and shown between parts (a) and (b). The numbers refer to the genetic organization of the genes. The regions amplified by PCR using each primer set, described in Table 2, are also depicted (c). The solid bars indicate the regions amplified; the dashed bars indicate the regions that failed to amplify. The numbers below the arrows indicate the names of the PCR primers used.

VC0514 (methyl-accepting chemotaxis protein) and VC0515 (hypothetical protein). At the time of its discovery, VSP-II was described as a $7.5 \mathrm{~kb}$ region encompassing eight ORFs (VC0490-VC0497). Later, O’Shea et al. (2004b) demonstrated that the $7.5 \mathrm{~kb}$ VSP-II region is part of a $29.6 \mathrm{~kb}$ island that encompasses ORFs VC0490-VC0516. In the initial study of Dziejman et al. (2002), a Peruvian strain C6709 was included but the absence of certain ORFs went unnoticed since at that time these ORFs were not considered as a part of the VSP-II region.

\section{VSP-II gene cluster sequence analysis}

The VSP-II gene cluster of one representative Peruvian strain Peru-130 was sequenced to gain better understanding of its gene content. When primer sets, $498 \mathrm{~F}$ and $490 \mathrm{R}, 490 \mathrm{~F}$ and 493R, 493F and 498R, 502F and 504R, and 47U and 517R, were used, PCR products of the expected sizes were obtained as shown in Fig. 1. When primer sets, 504F and 512R, 512F and $516 \mathrm{R}$, and $514 \mathrm{~F}$ and $517 \mathrm{R}$, were used, however, no amplicons were obtained. PCR primer set, VSPII LaU and VSPII LaR (designed using the DNA sequence obtained from PCR products amplified by $502 \mathrm{~F}$ and $504 \mathrm{R}$, and by $47 \mathrm{U}$ and $517 \mathrm{R}$, which encompass the negative region), produced an amplicon, which was close to the size of the prototype VSP-II of N16961 El Tor strain. Comparison of the obtained nucleotide sequences of the entire VSP-II including flanking regions (31 $299 \mathrm{bp}$ ) of PERU-130, and other parameters, with those of the of N16961 El Tor strain are shown in Fig. 1 and Table 5. Analysis showed that the $26.5 \mathrm{~kb}$ (26 $519 \mathrm{bp}$ ) VSP-II of PERU-130 contained 26 ORFs, which correspond to the $26.9 \mathrm{~kb}$ (26866 bp) containing 24 ORFs of N16961 El Tor strain (O'Shea et al., 2004b). In the VSP-II sequences from PERU-130 and N16961, four regions could be identified based on the extent of similarity. These were ORFs 2-14 of PERU130 (100\% similarity), ORFs 15-19 (94.4\% similarity), ORFs 20-24 (46.8\% similarity) and ORF 25 (89\% similarity) (Fig. 1). The sequencing data confirmed our PCR results, indicating that ORFs 20-24 of the Peruvian strain were, indeed, different from the corresponding VC0511-VC0515 region of NI6961.

The hypothetical proteins encoded by ORFs 20 and 21 showed 46.7 and $33.2 \%$ homology to proteins of Azoarcus sp. BH72, a mutualistic $\mathrm{N}_{2}$-fixing endophyte of rice and other grasses (Krause et al., 2006). ORF 22 representing another hypothetical protein that showed $46.7 \%$ homology to a protein encoded by a gene designated Mmcs_4842 of Mycobacterium sp. MCS (Table 5). The transposase OrfAB, subunit A, encoded by ORF 23 of PERU-130 showed $87.2 \%$ homology to a similar protein encoded by VCA0372 of NI6961, while subunit B of transposase OrfAB encoded by ORF 24 showed 83.6 and $86.1 \%$ homology to similar proteins of Nitrococcus mobilis Nb-231 and VCA0371 of $V$. cholerae N16961, respectively (Table 5). However, ORF 23 and ORF 24 (1214 bp) have high homology to $V$. cholerae serogroup O103 insertion sequences ISalg with $98.8 \%$ identity (Sozhamannan et al., 1999). ORF 25 of PERU-130 shared close homology to the phage integrase of Vibrio vulnificus YJ016 (98.5\%) and V. cholerae strain N16961 (93.7\%). The 5' flanking ORF 1 and the $3^{\prime}$ flanking ORF 26 of PERU-130 were identical to VC0489 and VC0517 of N16961 strain, respectively.

The complete nucleotide sequence analysis of VSP-II showed little difference in the overall size of the VSP-II of PERU-130 
Table 5. The 26 ORFs encompassing the $26.5 \mathrm{~kb}$ VSP-II island in V. cholerae O1 El Tor Peru-130 strain

\begin{tabular}{|c|c|c|c|c|c|c|c|c|c|}
\hline ORF & $\begin{array}{l}\text { Length in bp } \\
\text { (no. of aa) }\end{array}$ & Homologue & $\begin{array}{l}\text { Length in bp } \\
\text { (no. of aa) }\end{array}$ & $\begin{array}{l}\text { Amino acid } \\
\text { identity (\%) }\end{array}$ & $\begin{array}{l}\text { DNA identity } \\
(\%)\end{array}$ & $\begin{array}{c}\text { Gene } \\
\text { designation }\end{array}$ & Strain & Accession no. & Reference \\
\hline 1 & $1302(433)$ & Haemolysin & $1761(586)$ & 432/433 (99.8) & $1301 / 1302(99.9)$ & VC0489 & V. cholerae N16961 & NP_230143 & Heidelberg et al. (2000) \\
\hline 2 & $1962(653)$ & Hypothetical protein & $1962(653)$ & 653/653 (100) & 1962/1962 (100) & VC0490 & V. cholerae N16961 & NP_230144 & Heidelberg et al. (2000) \\
\hline 4 & $1164(388)$ & Hypothetical protein & $1164(388)$ & 388/388 (100) & $1164 / 1164(100)$ & VC0492 & V. cholerae N16961 & NP_230146 & Heidelberg et al. (2000) \\
\hline 5 & $876(291)$ & Hypothetical protein & $876(291)$ & 291/291 (100) & $876 / 876(100)$ & VC0493 & V. cholerae N16961 & NP_230147 & Heidelberg et al. (2000) \\
\hline 6 & $645(214)$ & Hypothetical protein & $645(214)$ & 214/214 (100) & $645 / 645(100)$ & VC0494 & V. cholerae N16961 & NP_230148 & Heidelberg et al. (2000) \\
\hline 7 & $675(224)$ & Hypothetical protein & $675(224)$ & 224/224 (100) & 675/675 (100) & VC0495 & V. cholerae N16961 & NP_230149 & Heidelberg et al. (2000) \\
\hline 10 & $441(146)$ & RNase $\mathrm{H}$ & 6) & $6 / 146(1$ & $1 / 441(1$ & $\mathrm{VCC}$ & V. cholerae N16961 & NP_230 & Heidelberg \\
\hline 11 & $525(174)$ & Type IV pilin & $525(174)$ & 174/174 (100) & $525 / 525(100)$ & VC0502 & V. cholerae N16961 & NP_230153 & Heidelberg et al. (2000) \\
\hline 12 & $1281(426)$ & Hypothetical protein & $1281(426)$ & $426 / 426(100)$ & $1281 / 1281(100)$ & VC0503 & V. cholerae N16961 & NP_230154 & Heidelberg et al. (2000) \\
\hline 13 & $228(75)$ & Hypothetical protein & $228(75)$ & $75 / 75(100)$ & $228 / 228(100)$ & VC0504 & V. cholerae N16961 & NP_230155 & Heidelberg et al. (2000) \\
\hline 14 & $369(122)$ & Hypothetical protein & $369(122)$ & 122/122(100) & $369 / 369(100)$ & VC0505 & V. cholerae N16961 & NP_230156 & Heidelberg et al. (2000) \\
\hline 15 & $735(244)$ & Hypothetical protein & $735(244)$ & 236/244 (96.7) & 708/735 (96.3) & VC0506 & V. cholerae N16961 & NP_230157 & Heidelberg et al. (2000) \\
\hline 16 & $177(58)$ & Hypothetical protein & $177(58)$ & $53 / 58(91.4)$ & 165/177 (93.2) & VC0507 & V. cholerae N16961 & NP_230158 & Heidelberg et al. (2000) \\
\hline \multirow[t]{2}{*}{18} & $444(147)$ & Hypothetical protein & $444(147)$ & $140 / 144(97.2)$ & $397 / 427(93.0)$ & VV0524 & V. vulnificus YJ016 & ZP_01482712 & Chen et al. (2003) \\
\hline & & & & 133/144 (92.4) & 398/434 (91.7) & VC0509 & V. cholerae N16961 & NP_230160 & Heidelberg et al. (2000) \\
\hline \multirow[t]{2}{*}{19} & $474(157)$ & $\begin{array}{l}\text { DNA repair protein } \\
\text { RadC family protein }\end{array}$ & $474(157)$ & $154 / 157(98.1)$ & $443 / 474(93.5)$ & VV0525 & V. vulnificus YJ016 & NP_933318 & Chen et al. (2003) \\
\hline & & & & $151 / 157(96)$ & $440 / 474(92.8)$ & VC0510 & N16961 & $\mathrm{NP}_{2}$ & Heidelb \\
\hline 20 & $1812(603)$ & Hypothetical protein & $1776(591)$ & 278/595 (46.7) & $982 / 1836(53.5)$ & azo2045 & Azoarcus sp. BH72 & YP_933549 & Krause et al. (2006) \\
\hline 21 & $2466(8$ & Hypothetical prot & 21 & & & azo2046 & BH72 & YP_933550 & Krause et al. (2006) \\
\hline 22 & $2043(673)$ & Hypothetical protein & $2043(680)$ & $319 / 683(46.7)$ & $1072 / 2054(52.2)$ & Mmcs_4842 & $\begin{array}{l}\text { Mycobacterium sp. } \\
\text { MCS }\end{array}$ & YP_642002 & Direct submission \\
\hline 23 & $345(114)$ & $\begin{array}{l}\text { Transposase OrfAB, } \\
\text { subunit A }\end{array}$ & $345(114)$ & 107/114 (93.9) & $300 / 345(87.2)$ & VCA0372 & V. cholerae N16961 & NP_232767 & Heidelberg et al. (2000) \\
\hline \multirow[t]{2}{*}{24} & $870(289)$ & $\begin{array}{l}\text { Transposase OrfAB, } \\
\text { subunit B }\end{array}$ & $921(306)$ & 265/289 (91.7) & $727 / 870(83.6)$ & NB231_17565 & N. mobilis Nb-231 & ZP_01128962 & Direct submission \\
\hline & & & $873(290)$ & 264/289 (91.3) & $749 / 870(86.1)$ & VCA0371 & V. cholerae N16961 & NP_232766 & Heidelberg et al. (2000) \\
\hline
\end{tabular}




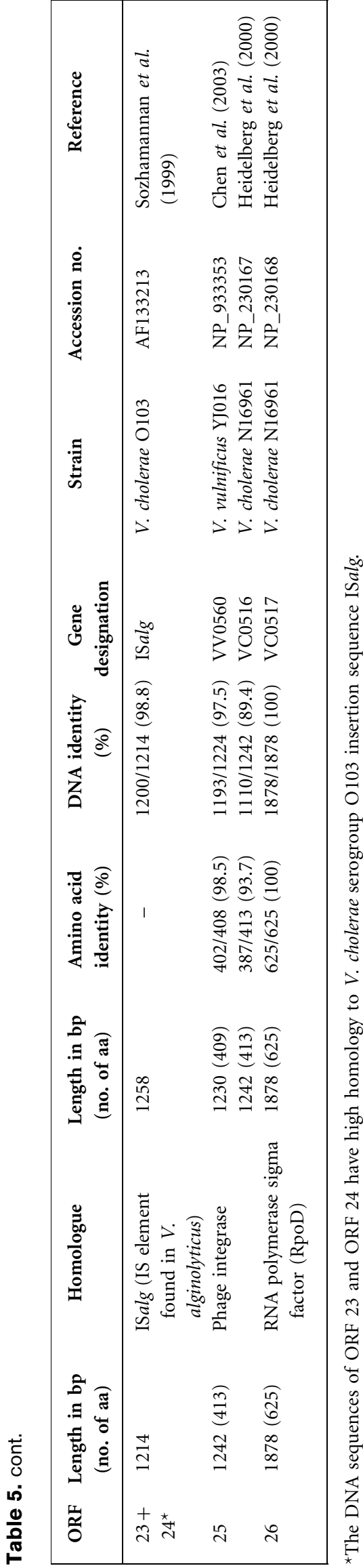

and NI6961 but the flanking regions were conserved. Of the 26 ORFs in the VSP-II of PERU-130, 20 showed extensive homology with the corresponding ORFs of N16961. Only one region comprising ORFs 20-24 of PERU-130 was different from the corresponding VSP-II region constituting VC0511-VC0515 of the prototype El Tor strain N16961. The presence of hypothetical proteins homologous to those present in the nitrogen-fixing endophyte symbiotic Azoarcus sp. in the VSP-II region (ORFs 20 and 21) indicates that the progenitor of the Peruvian $V$. cholerae strains may have acquired these genes from micro-organisms in the environment. The extensive DNA homology of ORFs 23 and 24 of the VSP-II of PERU-130 to $V$. cholerae serogroup O103 insertion sequence ISalg is interesting since ISalg is distributed in $69 \%$ of the $V$. cholerae non-O1 non-O139 strains, and has extensive homology to the IS element of Vibrio alginolyticus and IS911 of Shigella dysenteriae (Hayashi et al., 1997; Sozhamannan et al., 1999). We are not sure if these five divergent ORFs of PERU-130 assembled together or were independent acquisitions, but the presence of ISalg suggests genetic rearrangements or horizontal transfer.

\section{PFGE analysis}

In this study, PFGE analysis of the representative Peruvian strains isolated between 1991 and 1996 showed diverse PFGE banding patterns or pulsotypes (Fig. 2). Most of the pulsotypes were different from that of the reference O395 classical strain but similar to the N16961 El Tor strain, except pulsotype $\mathrm{Al}$, which is almost identical to the pulsotype of N16961.

The Latin American isolates, at the time of introduction, were clonal and were described as ET4 by multilocus enzyme electrophoresis (MLEE); the seventh pandemic strains in Asia and Africa belonged to ET3 (Wachsmuth et al., 1993). Later studies showed at least two distinct clones easily distinguishable by MLEE, ribotype, PFGE pattern and antimicrobial resistance pattern (Evins et al., 1995). By ribotyping, the Latin American epidemic was caused by strains of ribotype 5 , which were isolated from several other geographical locations but could be differentiated from the Latin American strains by other molecular typing techniques (Popovic et al., 1993). The evolution of $V$. cholerae O1 biotype El Tor strains isolated in Lima, Peru, from 1991 to 1995 showed the continuous and more frequent occurrence than previously, of genetic changes in the Latin American cholera epidemic strains (Dalsgaard et al., 1997). The Peruvian strains that we examined were isolated from the beginning of the epidemic in 1991 through 2003. Overall PFGE analysis revealed that the Peruvian strains are clonal and similar to the prototype seventh pandemic clone but different from the classical reference strain.

The origin and source of the Latin American strains of $V$. cholerae $\mathrm{O} 1$ in Peru remains a mystery. The 'single introduction hypothesis' states that the Latin American strains may have originated as a result of the emptying of 


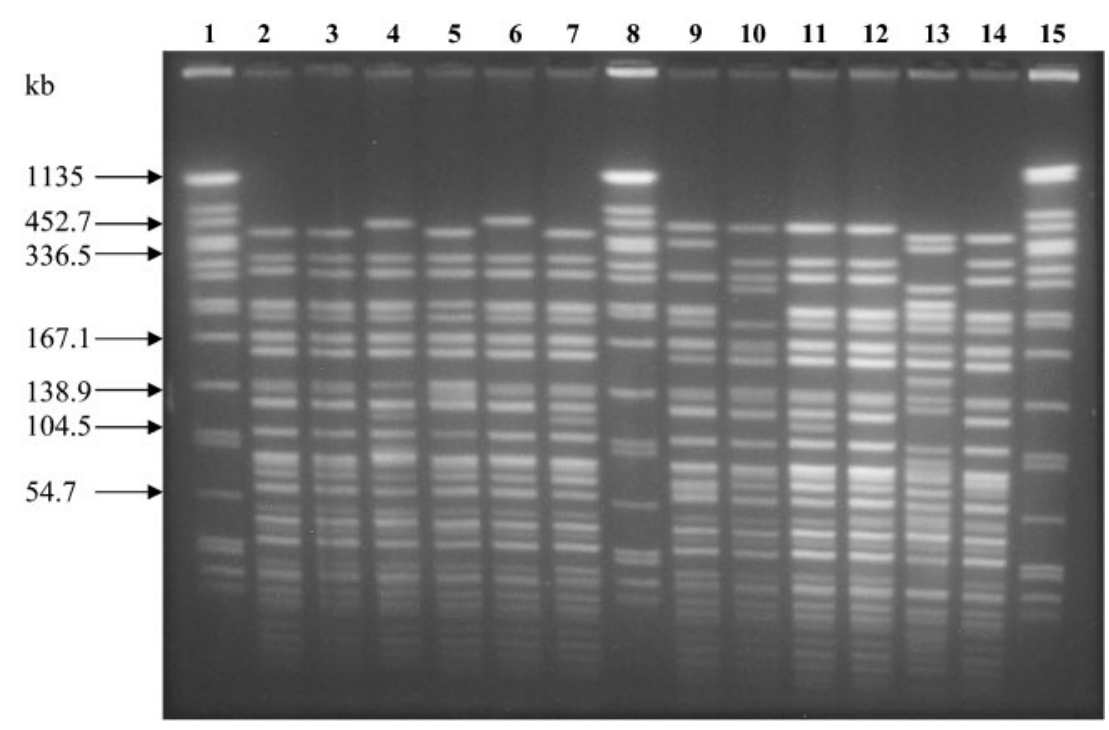

Fig. 2. Notl-restricted patterns of chromosomal DNA of Peruvian V. cholerae O1 El Tor strains isolated between 1991 and 1996. Lanes 1, 8 and 15, Salmonella braenderup strain $\mathrm{H} 9812$ as a molecular mass marker; lanes 2, 3 and 5, represent pulsotype A1 PERU-180 (1991), PERU-139 (1992) and PERU-067 (1993), respectively; lane 4, represents pulsotype B1 - PERU-011 (1993); lane 6, represents pulsotype B2 - PERU-086 (1994); lane 7, represents pulsotype A2 PERU-115 (1994); lane 9, represents pulsotype C - PERU-097 (1995); lane 10, represents pulsotype D - PERU-132 (1995); lane 11, represents pulsotype A3 - PERU-120 (1996); lane 12, represents pulsotype A4 PERU-137 (1996); and lanes 13 and 14, represent 569B classical and N16961 El Tor strains, respectively.

contaminated bilge waters of ships arriving from cholera endemic areas of Asia or Africa (McCarthy \& Khambaty, 1994). The difference in the VSP-II between the Peruvian strains and those from Asia and Africa does not support this hypothesis. Another, less-accepted hypothesis, consistent with simultaneous appearance of the disease in a number of coastal Peruvian sites within a few days, relates to the sudden and massive expansion of a pre-existing small population of pathogenic cholera vibrios on zooplankton or phytoplankton in Peruvian coastal waters (Craig, 1996). Once introduced into the coastal communities in concentrations large enough for human infection to occur, cholera spreads by the well-known means of contaminated water and food (Seas et al., 2000). The Peruvian strains may be genetic derivatives of $V$. cholerae $\mathrm{O} 1$ from the coastal environs of Peru because the VSP-II of environmental Peruvian strains from 1991 examined in this study were similar to all the clinical Peruvian strains and different from strains isolated from other countries and continents. Seas et al. (2000) also postulate that cholera vibrios, autochthonous to the aquatic environment, were present in multiple coastal locations, and this resulted from the environmental conditions that existed during an El Niño phenomenon.

The Peruvian El Tor O1 strains are genotypically not very distinct from the seventh pandemic Eurasian and African strains. The pulsotypes, while very different to the classical biotype, were very similar, almost indistinguishable, to $V$. cholerae O1 El Tor (see Peruvian pulsotypes A1 and N16961); all Peruvian strains contained VSP-I and part of VSP-II with identical flanking regions. It is difficult to accept that strains with this high similarity arose independently. VSP-II seems to be highly variable, in fact Peruvian strains differ within the VSP-II gene cluster; among the 60 strains examined 9 were positive for VC0511 and 20 were positive for VC0516. The presence of insertion elements suggests that the missing region in the Peruvian strains could be due to genetic rearrangements via horizontal transfer.

From a functional viewpoint, we do not know the significance of the difference between VSP-II of the Peruvian strains and those isolated from other continents. It is noteworthy that despite the genetic diversity, changing serotypes, and different year and place of isolation, the alteration in the VSP-II region of the Peruvian strains isolated for more than a decade was stably conserved. Therefore, from an identity point of view, this difference in the VSP-II lends a unique molecular signature to the Peruvian strains that could form the basis of tracking the origin of the Peruvian strains and therefore the Latin American pandemic. Based on the overall result obtained we suggest that it is more likely that the Peruvian and Eurasian and African strains belong to the same clonal complex, and the Peruvian strains represent variants that have independently evolved for a relatively short time. Optimally, we should have examined strains from other Latin American countries but did not do so since we had none in our collection. Further studies are required to understand what the difference means functionally.

\section{ACKNOWLEDGEMENTS}

This study was supported by grants provided to Ana Gil (Instituto de Investigación Nutricional) and G. B. Nair (ICDDR, B) from the Academy of Sciences for the Developing World (formerly the Third World Academy of Sciences), and by an International Cooperation Research Grant to Shinji Yamasaki (Osaka Prefecture University) and G. B. Nair (ICDDR, B) from the Ministry of Health, Labour, and Welfare, Japan. We also wish to thank Dr Cesar Munayco and Tania $\mathrm{H}$. Alarcon for graciously providing the environmental strains of $V$. cholerae from Peru. The views expressed in this article are those of the authors and do not necessarily reflect the official policy or position of 
the Department of the Navy, Department of Defense, nor the US Government.

\section{REFERENCES}

Chen, C. Y., Wu, K. M., Chang, Y. C., Chang, C. H., Tsai, H. C., Liao, T. L., Liu, Y. M., Chen, H. J., Shen, A. B. \& other authors (2003). Comparative genome analysis of Vibrio vulnificus, a marine pathogen. Genome Res 13, 2577-2587.

Chow, K. H., Ng, T. K., Yuen, K. Y. \& Yam, W. C. (2001). Detection of RTX toxin gene in Vibrio cholerae by PCR. J Clin Microbiol 39, 2594-2597.

Chowdhury, N. R., Chakraborty, S., Ramamurthy, T., Nishibuchi, M., Yamasaki, S., Takeda, Y. \& Nair, G. B. (2000). Molecular evidence of clonal Vibrio parahaemolyticus pandemic strains. Emerg Infect Dis 6, 631-636.

Cooper, K. L., Luey, C. K., Bird, M., Terajima, J., Nair, G. B., Kam, K. M., Arakawa, E., Safa, A., Cheung, D. T. \& other authors (2006). Development and validation of a PulseNet standardized pulsed-field gel electrophoresis protocol for subtyping of Vibrio cholerae. Foodborne Pathog Dis 3, 51-58.

Craig, J. P. (1996). Cholera: outlook for the twenty-first century. Caduceus 12, 25-42.

Dalsgaard, A., Skov, M. N., Serichantalergs, O., Echeverria, P., Meza, R. \& Taylor, D. N. (1997). Molecular evolution of Vibrio cholerae O1 strains isolated in Lima, Peru, from 1991 to 1995. J Clin Microbiol 35, 1151-1156.

Davis, B. M., Kimsey, H. H., Chang, W. \& Waldor, M. K. (1999). The Vibrio cholerae $\mathrm{O} 139$ Calcutta bacteriophage $\operatorname{CTX} \varphi$ is infectious and encodes a novel repressor. J Bacteriol 181, 6779-6787.

Dziejman, M., Balon, E., Boyd, D., Fraser, C. M., Heidelberg, J. F. \& Mekalanos, J. J. (2002). Comparative genomic analysis of Vibrio cholerae: genes that correlate with cholera endemic and pandemic disease. Proc Natl Acad Sci U S A 99, 1556-1561.

Evins, G. M., Cameron, D. N., Wells, J. G., Greene, K. D., Popovic, T., Giono-Cerezo, S., Wachsmuth, I. K. \& Tauxe, R. V. (1995). The emerging diversity of the electrophoretic types of Vibrio cholerae in the Western hemisphere. J Infect Dis 172, 173-179.

Hayashi, M., Fujii, J. \& Unemoto, T. (1997). Genetic defect of the sodium pump-defective mutant nap-1 from the marine Vibrio alginolyticus. Biochem Mol Biol Int 41, 41-47.

Heidelberg, J. F., Eisen, J. A., Nelson, W. C., Clayton, R. A., Gwinn, M. L., Dodson, R. J., Haft, D. H., Hickey, E. K., Peterson, J. D. \& other authors (2000). DNA sequence of both chromosomes of the cholera pathogen Vibrio cholerae. Nature 406, 477-483.

Hoshino, K., Yamasaki, S., Mukhopadhyay, A. K., Chakraborty, S., Basu, A., Bhattacharya, S. K., Nair, G. B., Shimada, T. \& Takeda, Y. (1998). Development and evaluation of a multiplex PCR assay for rapid detection of toxigenic Vibrio cholerae O1 and O139. FEMS Immunol Med Microbiol 20, 201-207.

Kaper, J. B., Morris, J. G., Jr \& Levine, M. M. (1995). Cholera. Clin Microbiol Rev 8, 48-86.

Karaolis, D. K., Johnson, J. A., Bailey, C. C., Boedeker, E. C., Kaper, J. B. \& Reeves, P. R. (1998). A Vibrio cholerae pathogenicity island associated with epidemic and pandemic strains. Proc Natl Acad Sci U S A 95, 3134-3139.

Keasler, S. P. \& Hall, R. H. (1993). Detecting and biotyping V. cholerae O1 with multiplex polymerase chain reaction. Lancet 341, 1661.

Kovach, M. E., Shaffer, M. D. \& Peterson, K. M. (1996). A putative integrase gene defines the distal end of a large cluster of ToxRregulated colonization genes in Vibrio cholerae. Microbiology 142, 2165-2174.
Krause, A., Ramakumar, A., Bartels, D., Battistoni, F., Bekel, T., Boch, J., Böhm, M., Friedrich, F., Hurek, T. \& other authors (2006). Complete genome of the mutualistic, N2-fixing grass endophyte Azoarcus sp. strains BH72. Nat Biotechnol 24, 1385-1391.

McCarthy, S. A. \& Khambaty, F. M. (1994). International dissemination of epidemic Vibrio cholerae by cargo ship ballast and other nonpotable waters. Appl Environ Microbiol 60, 2597-2601.

Mitra, R. K., Nandy, R. K., Ramamurthy, T., Bhattacharya, S. K., Yamasaki, S., Shimada, T., Toshio, S., Takeda, Y. \& Nair, G. B. (2001). Molecular characterization of rough variants of Vibrio cholerae isolated from hospitalised patients with diarrhoea. J Med Microbiol 50, 268-276.

Nair, G. B., Faruque, S. M., Bhuiyan, N. A., Kamruzzaman, M., Siddique, A. K. \& Sack, D. A. (2002). New variants of Vibrio cholerae O1 biotype El Tor with attributes of the classical biotype from hospitalized patients with acute diarrhea in Bangladesh. J Clin Microbiol 40, 3296-3299.

Nair, G. B., Safa, A., Bhuiyan, N. A., Nusrin, S., Murphy, D., Nicol, C., Valcanis, M., Iddings, S., Kubuabola, I. \& Vally, H. (2006). Isolation of Vibrio cholerae O1 strains similar to pre-seventh pandemic El Tor strains during an outbreak of gastrointestinal disease in an island resort in Fiji. J Med Microbiol 55, 1559-1562.

Nandi, B., Nandy, R. K., Mukhopadhyay, S., Nair, G. B., Shimada, T. \& Ghose, A. C. (2000). Rapid method for the species-specific identification of Vibrio cholerae using primers targeted to the gene of outer membrane protein OmpW. J Clin Microbiol 38, 4145-4151.

Nusrin, S., Khan, G. Y., Bhuiyan, N. A., Ansaruzzaman, M., Hossain, M. A., Safa, A., Khan, R., Faruque, S. M., Sack, D. A. \& other authors (2004). Diverse CTX phages among toxigenic Vibrio cholerae O1 and O139 strains isolated between 1994 and 2002 in an area where cholera is endemic in Bangladesh. J Clin Microbiol 42, 5854-5856.

O'Shea, Y. A., Reen, F. J., Quirke, A. M. \& Boyd, E. F. (2004a). Evolutionary genetic analysis of the emergence of epidemic Vibrio cholerae isolates based on comparative nucleotide sequence analysis and multilocus virulence gene profiles. J Clin Microbiol 42, 46574671.

O'Shea, Y. A., Finnan, S., Reen, F. J., Morrissey, J. P., O'Gara, F. \& Boyd, E. F. (2004b). The Vibrio seventh pandemic island-II is a 26.9 $\mathrm{kb}$ genomic island present in Vibrio cholerae $\mathrm{El}$ Tor and $\mathrm{O} 139$ serogroup isolates that shows homology to a $43.4 \mathrm{~kb}$ genomic island in V. vulnificus. Microbiology 150, 4053-4063.

Popovic, T., Bopp, C., Olsvik, O. \& Wachsmuth, I. K. (1993). Epidemiologic application of a standardized ribotype scheme for Vibrio cholerae O1. J Clin Microbiol 31, 2474-2482.

Rivera, I. N., Chun, J., Huq, A., Sack, R. B. \& Colwell, R. R. (2001). Genotypes associated with virulence in environmental isolates of Vibrio cholerae. Appl Environ Microbiol 67, 2421-2429.

Safa, A., Bhuiyan, N. A., Nusrin, S., Ansaruzzaman, M., Alam, M., Hamabata, T., Takeda, Y., Sack, D. A. \& Nair, G. B. (2006). Genetic characteristics of Matlab variants of Vibrio cholerae O1 that are hybrids between classical and El Tor biotypes. J Med Microbiol 55, 1563-1569.

Seas, C., Miranda, J., Gil, A. I., Leon-Barua, R., Patz, J., Huq, A., Colwell, R. R. \& Sack, R. B. (2000). New insights on the emergence of cholera in Latin America during 1991: the Peruvian experience. Am J Trop Med Hyg 62, 513-517.

Sozhamannan, S., Deng, Y. K., Li, M., Sulakvedidze, A., Kaper, J. B., Johnson, J. A., Nair, G. B. \& Morris, J. G., Jr (1999). Cloning and sequencing of the genes downstream of the $w b f$ gene cluster of Vibrio cholerae serogroup $\mathrm{O} 139$ and analysis of the junction genes in other serogroups. Infect Immun 67, 5033-5040. 
Tauxe, R. V., Mintz, E. D. \& Quick, R. E. (1995). Epidemic cholera in the New World: translating field epidemiology into new prevention strategies. Emerg Infect Dis 1, 141-146.

Trucksis, M., Michalski, J., Deng, Y. K. \& Kaper, J. B. (1998). The Vibrio cholerae genome contains two unique circular chromosomes. Proc Natl Acad Sci U S A 95, 14464-14469.
Wachsmuth, I. K., Evins, G. M., Fields, P. I., Olsvik, Ø̈., Popovic, T., Bopp, C. A., Wells, J. G., Carrillo, C. \& Blake, P. A. (1993). The molecular epidemiology of cholera in Latin America. J Infect Dis 167, 621-626.

Waldor, M. K. \& Mekalanos, J. J. (1996). Lysogenic conversion by a filamentous phage encoding cholera toxin. Science 272, 1910-1914. 